surveillance of healthcare workers following documented exposures to HIV-infected blood; HIV seroprevalence surveys in surgeons; evaluation of the use of zidovudine prophylaxis in healthcare workers following exposure to HIV; and development of guidelines to protect healthcare workers and patients from nosocomial acquisition of HIV and HIV-related infections.

The incumbent would be the lead epidemiologist responsible for one or more epidemiologic studies of the following areas: studying the risk of transmission of HIV and HIV-associated opportunistic infections from patients to healthcare workers, patients to patients, and healthcare workers to patients; designing and evaluating strategies to protect healthcare workers and patients from nosocomial infection with HIV and HIV-associated opportunistic infections; evaluating the safety and efficacy of postexposure prophylaxis of HIV infection with zidovudine and other agents; studying the risk and prevention of nosocomial infections in patients with HIV infection; and conducting "lookback studies" to assess the risk of HIV

transmission to patients who have undergone invasive procedures by HIV-infected healthcare workers.

An MD degree and EIS or comparable epidemiologic training/experience is desirable. For additional information about the position, contact Mary E. Chamberland, MD, Chief, Epidemiologic Studies Unit, AIDS Activity, HIP or David M. Bell, MD, Chief AIDS Activity, HIP at (404) 639-1644.

\title{
Job Board-Infection Control Practitioners
}

The Los Angeles CountyUniversity of Southern California Medical Center has two positions open for nurse epidemiologists. The infection control program is well established with five nurse epidemiologists, three clerical staff, and a full-time physician.
The hospital, a large primary-care institution, is the principal teaching hospital of the University of Southern California. Los Angeles County is an equal opportunity employer. Applicants should have a BSN and several years of experience in infection control or public health. For more information please contact Peter Heseltine, MD, LAC + USC, Box 596, 1200 North State Street, Los Angeles, CA 90033-1084.

Telephone (213) 2266705 or FAX (213) 2267726.

\section{SHEA/CDC/AHA Hospital Epidemiology Course}

The May 1619, 1991, offering of this course is completely filled! The course, which emphasizes hands-on problem solving, has been enlarged to accommodate approximately 100 attendees, and there is still a large number of individuals who were not able to register.
More next month on the course and the response of the sponsoring organizations to this high level of interest. 


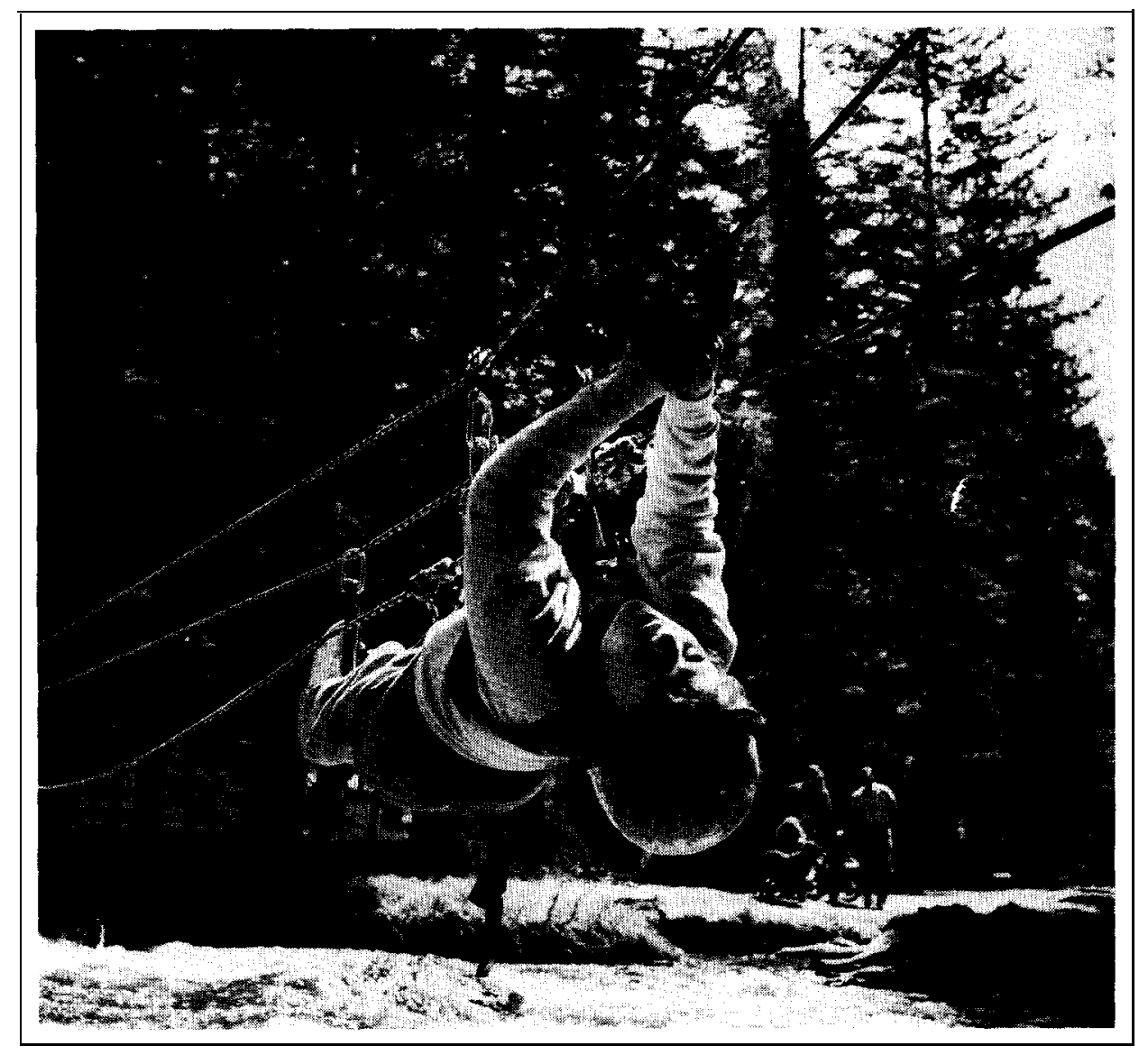

\section{There are some things you just can't do from a wheelchair.}

Like traversing a river. Or riding a horse.

Climbing a tree. Or biking.

And Bridget does all these at an Easter Seal camp.

Join Bridget in the adventure of a lifetime.

Be a summer camp nurse for children and adults with disabilities.

Give The Power To Overcome.

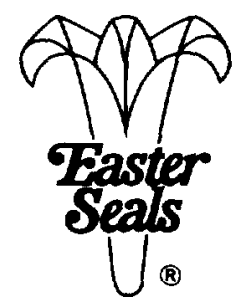


This space is contributed as a public senvice.

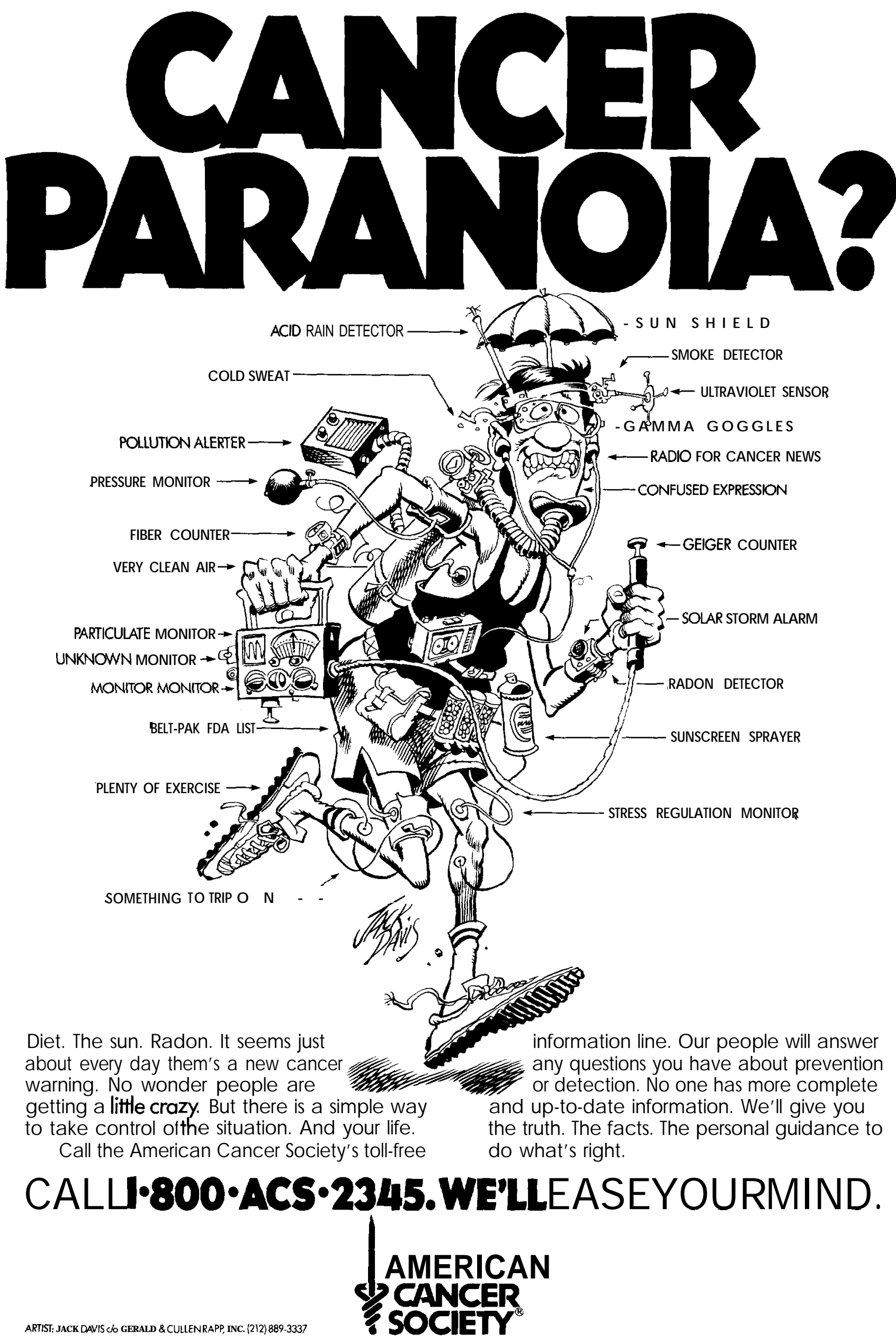

Created as a public service by Tucker Wayne/Luckie. 